\title{
La LIJ de enhorabuena: Entrevista con Manuela Rodríguez y Xosé Ballesteros'
}

Interview with Manuela Rodríguez y Xosé Ballesteros

\author{
MAR CAMPOS F.-FÍGARES \\ Universidad de Almería \\ España \\ mcampos@ual.es \\ CRISTINA FALCÓN MALDONADO \\ Venezuela \\ info@veoveoc.es
}

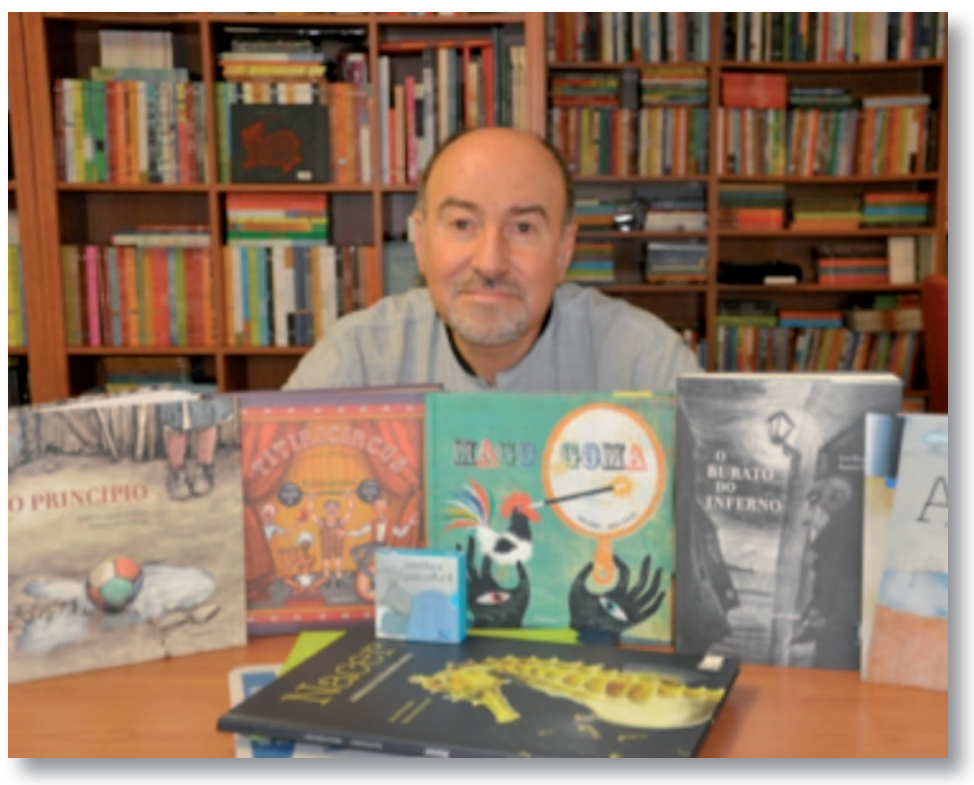

Desde que en 1998 un grupo de amigos se plantearan llenar el vacío existente en la literatura infantil gallega-publicando libros en esta lengua- hasta el año presente en el que Kalandraka ha recibido el Premio Nacional a la Mejor Labor Editorial Cultural 2012, han cambiado muchas cosas y a la vez ninguna: la editorial ha crecido, se ha hecho políglota en la Península y ha saltado con rotundidad al ámbito internacional. Lo que no se ha alterado es la extrema calidad de las obras que nos regalan a los lectores: abrir un libro de Kalandraka nunca decepciona, al contrario. El reconocimiento del Ministerio de Cultura llega después de que esta editorial se hubiera consolidado, indiscutiblemente, como una de las más apreciadas tanto por profesionales dedicados a la LIJ como por los lectores, que se acercan a sus libros con la certeza de estar ante pequeñas obras maestras. En Álabe hemos querido hablar con dos de las personas que más trascendencia han tenido en la promoción de la literatura infantil y juvenil desde su valioso trabajo editorial.

\footnotetext{
I Para citar este artículo: Campos F.-Fígares, M. y Falcón Maldonado, C. (2OI2). La LIJ de Enhorabuena: Entrevista con Manuela Rodríguez y Xosé Ballesteros. Alabe 6. [www.revistaalabe.com] (Recibido 05-I2-2OI2; aceptado 27-I2-2OI2)
} 
P. Editar es comprometerse, y recibir un premio tan importante como el Premio Nacional -premio que nunca antes se había otorgado a una editorial especializada en literatura infantil y juvenil- es, a la vez, un reconocimiento a la labor realizada y un desafío hacia el porvenir... ¿Cómo y quiénes hacen los “Libros para soñar”?

R. En Kalandraka trabajamos un grupo de personas que apostamos firmemente por la formación lectora de los más pequeños. Creemos firmemente que, siendo buenos lectores, podrán llegar a ser ciudadanos críticos y más libres. Como decía Gianni Rodari, no procuramos que todos los niños y niñas lleguen a ser escritores, simplemente deseamos que ninguno sea esclavo.

P. Ustedes acaban de volver de la Feria Internacional del Libro de Guadalajara. Kalandraka hace mucho que trabaja con países iberoamericanos. ¿Perciben diferencias notables entre los lectores de aquel lado y los de éste?

R. Llevamos más de doce años participando en ferias en Iberoamérica. Lo más destacable que notamos entre España y los países americanos (con todas las diferencias que hay entre ellos) es el difícil acceso a la cultura para muchas de las personas que viven en Latinoamérica, los que quisieran ser lectores y no pueden porque no tienen recursos económicos, porque viven en la pobreza. Algunos gobiernos están realizando un trabajo destacado con Planes Nacionales de Lectura, con programas para la mejora de su red bibliotecaria, pero aún queda mucho por hacer. En España lo más notable es que todos los logros en el llamado "estado del bienestar", conseguidos en las últimas décadas, se están cuestionando y los recortes ya afectan a la red de bibliotecas públicas; eso se va a notar para peor.

P. Un repaso al cuidado catálogo de Kalandraka pone de manifiesto que la literatura infantil actual está muy lejos de las limitaciones temáticas que tenía hace no tantos años, de la que se libraban pocos países. Pero, ¿considera usted que hay temas que no se deben tratar en la literatura infantil, o temas que aún no se han sabido recoger en los textos dedicados a los más pequeños?

R. En nuestro catálogo no hay temas prohibidos ni tabúes, pero somos conscientes de qué es lo que más interesa a los pequeños lectores y lo que menos. Lo complicado es acercarles aquellos temas que, a priori, parecen no tener interés, pero realmente lo que hay es desconocimiento.

P. Volviendo a las temáticas que aparecen en las obras que ustedes editan, hay algunas difíciles sobre la pobreza, el derecho a la educación, problemas que aquí veíamos con cierta distancia hasta hace poco. Hoy estremece conocer el aumento de la pobreza en todos los niveles y especialmente la infantil en España. ¿Qué papel cumple o puede cumplir la literatura y su lectura, cuál debe ser el lugar de la cultura en estos días? 
R. El que ha cumplido siempre: emocionar, educar, divertir, provocar, ayudarles a descubrir el mundo y a entender la realidad... un poquito.

P. Según los resultados de las últimas ferias del libro, la publicación de libros para niños y jóvenes goza de buena salud y se reafirma por su valor en sí misma. Podría decirse que es el sector más prometedor dentro del panorama de la edición ¿Se lee más en época de crisis?

R. No creo que se lea ni más ni menos porque haya crisis. Y hay dos factores a tener en cuenta cuando se habla de LIJ: el primero tiene que ver con la educación. Como en todos los países occidentales, en los colegios españoles hay lecturas recomendadas. Este es un mercado al que todas las editoriales desean llegar; algunas, especialmente las que son titularidad de las órdenes religiosas, lo tienen más fácil porque actúan directamente en los colegios de su propiedad. No hay menos niños en los colegios, por tanto, no hay menos lectores potenciales. En segundo lugar, las familias desean lo mejor para sus hijos, y un valor en alza a nivel social es que los niños lean, que sean buenos lectores. Estos dos factores, en mi opinión, tienen mucho que ver con la "buena salud” de la LIJ.

P. Sabemos que ustedes ponen el máximo interés en seleccionar un ilustrador específico para cada texto, en la apuesta gráfica y en la educación no sólo literaria sino también visual a través de sus libros ¿̇de qué manera realizan esta conjunción entre artistas, hasta qué punto el editor interviene en este proceso?

R. Depende del libro. Hay proyectos que ya son presentados por autor e ilustrador y otros donde el equipo de edición tiene que encontrar el tándem ideal. En un álbum ilustrado, como decía Maurice Sendak, no se deben ver las “puntadas”. Para ello es importante comprender que elaborar un libro de este tipo se convierte en un proceso dialéctico donde el editor es el nexo entre los autores del texto y las ilustraciones.

P. Su editorial, como no podía ser de otra manera, tiene página web, blog, etc... ¿Cree que esto ha permitido una relación más profunda con los lectores o no necesariamente? ¿Cuál cree que es el resultado de la presencia en el entorno digital de una editorial que defiende al máximo la edición en papel?

R. Los avances tecnológicos permiten mejores condiciones de trabajo en el ámbito de la producción y de la comunicación entre todos los agentes que operan en el sector del libro. Y la presencia activa en las redes sociales, el mantenimiento del blog y una web actualizada, una relación más directa con autores y potenciales lectores, en definitiva, una mayor difusión y promoción del libro, pero casi siempre en ámbito concreto de especialistas o entusiastas del álbum ilustrado y la LIJ. 
P. ¿Y la poesía? ¿La apuesta por la poesía ha valido la pena? Esa apuesta que ha sido destacada especialmente a la hora de otorgarles el Premio Nacional a la Labor Editorial este año 2OI2?

R. En Kalandraka apostamos por la buena literatura, y la poesía está en los cimientos de la literatura, no es un género ajeno a ella. La poesía está presente en cuanto se abre nuestro catálogo: la colección "De la cuna a la luna" es una propuesta basada en el concepto de pictograma poético o "poegrama”, creada especialmente para los pre-lectores, como dice su autor: son libros "para educar el ojo y endulzar el oído". Con esto cabe destacar que no "apostamos" por la poesía, puesto que la poesía "es" una parte (importante) más de nuestro catálogo.

P. Una pregunta más. Ustedes otorgan cada año un premio de poesía para niños, el "Ciudad de Orihuela" y otro al mejor álbum ilustrado, "Premio Compostela". ¿Pueden hablarnos un poco sobre las obras galardonadas en la última edición de los premios? ¿Qué hallazgos les comportan estas dos convocatorias a nivel editorial?

R. Palabras para armar tu canto es la obra ganadora de la quinta edición del Premio Internacional Ciudad de Orihuela de Poesía para Niños. Ramón Suárez Caamal es un autor de mucho prestigio en México, con una amplia y reconocida trayectoria literaria. Su poemario, ilustrado con mucho talento por su compatriota Cecilia Rébora, contiene versos que van desde la tradición oral, hasta los juegos de palabras y composiciones de gran calidad inspiradas en la poesía del Siglo de Oro español. Bandada, de María Julia Díaz y David Daniel Álvarez, galardonada con el V Premio Internacional Compostela de Álbum Ilustrado, es una metáfora crítica sobre la historia de la humanidad, que destaca por sus extraordinarias ilustraciones, realizadas con lápiz de grafito. Estos certámenes nos permiten descubrir nuevos creadores y poder publicar obras de autores de cualquier país. Para muchos de ellos es una gran oportunidad de darse a conocer.
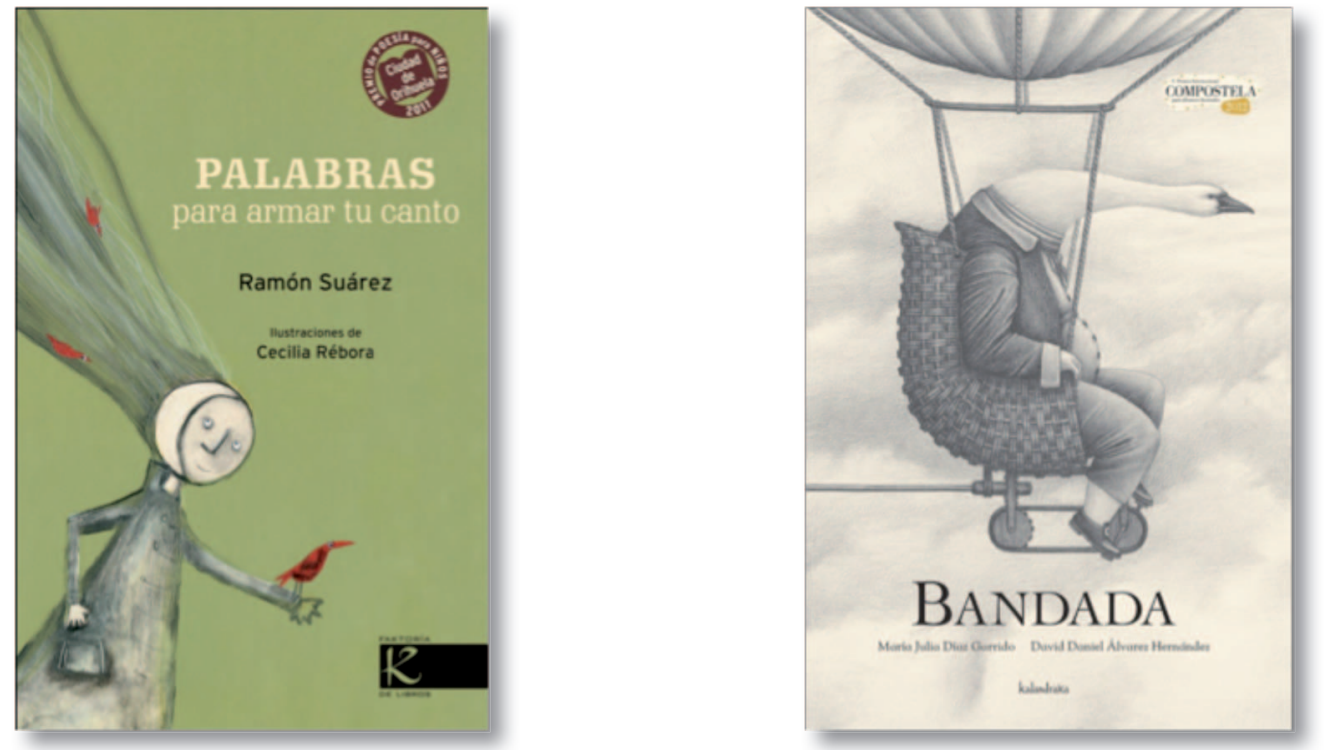